\title{
Therapeutic Drug Monitoring to Guide Clinical Decision Making in Inflammatory Bowel Disease Patients with Loss of Response to Anti-TNF: A Delphi Technique-Based Consensus
}

\author{
Greuter, Thomas ; Maillard, Michel H ; Juillerat, Pascal ; Michetti, Pierre ; Seibold, Frank ; Mottet, \\ Christian ; Zahnd, Nadine ; Sauter, Bernhard ; Schoepfer, Alain M ; Rogler, Gerhard ; Vavricka, \\ Stephan R
}

\begin{abstract}
BACKGROUND Loss of response is frequently encountered in patients with inflammatory bowel disease (IBD) treated with antitumor necrosis factor (TNF) agents. Therapeutic drug monitoring (TDM) and antidrug antibody measurement are increasingly used in this setting. METHODS To establish a consensus on the use of TDM in the context of loss of response to anti-TNFs, we performed a vote using a Delphi-style process followed by an expert panel discussion among 8 IBD specialists practicing in Switzerland, Europe. Statements were rated on an even Likert-scale ranging from 1 (strong disagreement) to 4 (strong agreement), based on expert opinion and the available literature. RESULTS The experts agreed on the following statements: (i) loss of response is associated with inadequate drug levels in both Crohn's disease and ulcerative colitis; (ii) best timepoint for measuring drug levels is prior to the next application (= trough levels) with different thresholds for anti-TNF agents (infliximab $5 \mathrm{~g} / \mathrm{mL}$, adalimumab $8 \mathrm{~g} / \mathrm{mL}$, certolizumab pegol $10 \mathrm{~g} / \mathrm{mL}$ ); (iii) antidrug antibodies are predictive for loss of response; and (iv) antidrug-antibody titers and drug trough levels are key determinants in the treatment algorithm. Data about non-anti-TNF biologics were considered too limited to propose recommendations. CONCLUSION A Delphi-style consensus among 8 IBD experts shows that TDM and measurement of antidrug-antibody titers are useful in the context of loss of response to anti-TNF. Optimal cutoff levels depend on the type of anti-TNF. These values are critical in the decision making process. More studies are needed to address the value of such measurements for non-anti-TNF biologics.
\end{abstract}

DOI: https://doi.org/10.1159/000501930

Posted at the Zurich Open Repository and Archive, University of Zurich ZORA URL: https://doi.org/10.5167/uzh-178717

Journal Article

Published Version

Originally published at:

Greuter, Thomas; Maillard, Michel H; Juillerat, Pascal; Michetti, Pierre; Seibold, Frank; Mottet, Christian; Zahnd, Nadine; Sauter, Bernhard; Schoepfer, Alain M; Rogler, Gerhard; Vavricka, Stephan R (2020). Therapeutic Drug Monitoring to Guide Clinical Decision Making in Inflammatory Bowel Disease Patients with Loss of Response to Anti-TNF: A Delphi Technique-Based Consensus. Digestion, 101(6):683-691.

DOI: https://doi.org/10.1159/000501930 


\title{
Therapeutic Drug Monitoring to Guide Clinical Decision Making in Inflammatory Bowel Disease Patients with Loss of Response to Anti-TNF: A Delphi Technique-Based Consensus
}

\author{
Thomas Greuter $^{\mathrm{a}}$ Michel H. Maillard ${ }^{\mathrm{b}, \mathrm{c}}$ Pascal Juillerat ${ }^{\mathrm{d}}$ \\ Pierre Michetti $^{c}$ Frank Seibold $^{\mathrm{e}}$ Christian Mottet $^{f}$ Nadine Zahnd $^{\mathrm{g}}$ \\ Bernhard Sauter $^{\text {h }}$ Alain M. Schoepfer ${ }^{b}$ Gerhard Rogler ${ }^{a}$ \\ Stephan R. Vavricka ${ }^{a}$ i on behalf of the Swiss IBDnet, an official working group of \\ the Swiss Society of Gastroenterology

\begin{abstract}
${ }^{a}$ Department of Gastroenterology and Hepatology, University Hospital Zurich, Zurich, Switzerland; b Division of Gastroenterology and Hepatology, University Hospital Lausanne - CHUV, Lausanne, Switzerland; ' ${ }^{\circ}$ Crohn and Colitis Center, Gastroentérologie Beaulieu SA, Lausanne, Switzerland; d Gastroenterology, Clinic for Visceral Surgery and Medicine, Inselspital, University Hospital of Bern, Bern, Switzerland; ' Crohn-Colitis Zentrum, Hochhaus Lindenhofspital, Bern, Switzerland; ' Division of Gastroenterology, Hopital de Sion, Sion, Switzerland; 9IBDnet, Zurich, Switzerland; h Gastrozentrum Hirslanden, Hirslanden Private Clinic Group, Zurich, Switzerland; 'Zentrum für Gastroenterologie und Hepatologie, Zurich, Switzerland
\end{abstract}

\section{Keywords}

Therapeutic drug monitoring • Antidrug antibodies · Inflammatory bowel disease - Loss of response .

Consensus - Antitumor necrosis factor

\begin{abstract}
Background: Loss of response is frequently encountered in patients with inflammatory bowel disease (IBD) treated with antitumor necrosis factor (TNF) agents. Therapeutic drug monitoring (TDM) and antidrug antibody measurement are increasingly used in this setting. Methods: To establish a consensus on the use of TDM in the context of loss of response to anti-TNFs, we performed a vote using a Delphistyle process followed by an expert panel discussion among 8 IBD specialists practicing in Switzerland, Europe. State-
\end{abstract}

() 2019 S. Karger AG, Basel

E-Mail karger@karger.com www.karger.com/dig ments were rated on an even Likert-scale ranging from 1 (strong disagreement) to 4 (strong agreement), based on expert opinion and the available literature. Results: The experts agreed on the following statements: (i) loss of response is associated with inadequate drug levels in both Crohn's disease and ulcerative colitis; (ii) best timepoint for measuring drug levels is prior to the next application (= trough levels) with different thresholds for anti-TNF agents (infliximab $5 \mu \mathrm{g} / \mathrm{mL}$, adalimumab $8 \mu \mathrm{g} / \mathrm{mL}$, certolizumab pegol $10 \mu \mathrm{g} /$ $\mathrm{mL}$ ); (iii) antidrug antibodies are predictive for loss of response; and (iv) antidrug-antibody titers and drug trough levels are key determinants in the treatment algorithm. Data about non-anti-TNF biologics were considered too limited to

T.G. and M.H.M. contributed equally to this work.
Prof. Dr. med. Stephan R. Vavricka

Zentrum für Gastroenterologie und Hepatologie

Vulkanplatz 8

CH-8048 Zürich (Switzerland)

E-Mail vavricka@zgh.ch 
propose recommendations. Conclusion: A Delphi-style consensus among 8 IBD experts shows that TDM and measurement of antidrug-antibody titers are useful in the context of loss of response to anti-TNF. Optimal cutoff levels depend on the type of anti-TNF. These values are critical in the decision making process. More studies are needed to address the value of such measurements for non-anti-TNF biologics.

(c) 2019 S. Karger AG, Basel

\section{Introduction}

Inflammatory bowel disease (IBD) with its 2 subtypes Crohn's disease (CD) and ulcerative colitis (UC) is a chronic inflammatory disorder of the gastrointestinal tract [1]. Given a complex and yet only partially understood etiopathogenesis, IBD is considered an incurable, but treatable disease [2,3]. The introduction of antitumor necrosis factor (TNF) with considerable higher efficacy than conventional immunomodulatory drugs has dramatically changed the therapeutic management of IBD. However, loss of response is encountered in up to $46 \%$ of IBD patients treated with anti-TNF $[4,5]$. Loss of response implies a previous initial response to treatment, which is lost over time, and has to be differentiated from primary nonresponse, where such response is never achieved [4]. To undermine this difference, loss of response is sometimes referred to as secondary nonresponse. Based on the mechanisms involved, loss of response can be either classified as immune-mediated (formation of antibodies against anti-TNF) or nonimmune mediated (accelerated drug clearance due to burden of disease, weight or male gender, nonadherence, fibrostenotic disease phenotype) [4]. Therapeutic drug monitoring (TDM) and antidrug antibody measurement are increasingly used in the setting of a loss of response and data supporting their application in daily practice are emerging [6-8]. However - despite acknowledging the usefulness of TDM - current guidelines of the European Crohn's and Colitis Organisation (ECCO) lack of a clear recommendation regarding optimal time-point, adequate thresholds, and TDM's exact role in the long-term therapeutic algorithm $[9,10]$.

Therefore, we performed an expert panel discussion to reach a consensus statement based on the available literature about TDM. The goal of this discussion was to elaborate an algorithm for TDM in the context of biological therapy in IBD and a loss of response to such treatment. During an expert meeting, the relevance of thresholds and cutoff values for adequate drug concentrations and antidrug-antibody titers were discussed, and a therapeutic decision pathway was elaborated. The discussion focused on TDM for loss of response only, so therapy monitoring per se was not within the scope of the panel discussion. With this consensus study, we sought to answer the following questions: (1) when and why to measure and how to interpret drug levels? (2) when and why to measure and how to interpret antidrug antibody titers? and finally, and (3) what is the best treatment algorithm in case of a loss of response to anti-TNF?

\section{Literature Review}

\section{Definition of Loss of Response}

There is no universally accepted definition of loss of response to anti-TNF treatment and hence its reported frequency is highly variable. Definitions used in clinical trials, observational studies, and reviews are (1) reemergence of clinical symptoms after induction of response, verified by an increase in clinical activity scores such as the Crohn's disease activity index (CDAI, e.g., 70 point change) or Mayo score (e.g., 3 point change) [11, 12]; (2) patient's perspective of increasing symptoms [13]; and (3) need for dose intensification or treatment discontinuation with a switch to other agents $[5,14,15]$. Current ECCO guidelines suggest the following 2 possible definitions for loss of response in CD - acknowledging that no consensus exists: For CD (1) a CDAI >150 with an increase of $>70$ points or (2) a CDAI increase of $\geq 100$ points [9]; For UC, ECCO did not release a statement regarding the definition of loss of response [10]. However, a Mayo score of $>2$ or an increase of 3 or more points might be used in daily clinical practice $[16,17]$.

\section{Drug Levels and Loss of Response}

Several studies demonstrated higher efficacy of antiTNFs with higher serum drug levels, both in UC and CD, as well as for infliximab and other anti-TNF agents. Most data derive from retrospective analyses of prospective trials, which have been nicely summarized in a comprehensive review by Sorrentino et al. [18] In CD, high or detectable infliximab trough levels were associated with higher rates of ongoing clinical response compared to low or undetectable levels. These rates were (1) 82 vs. $6 \%$ (for detectable vs. nondetectable) [19]; (2) 74 vs. $59 \%$ (for cutoff $>3 \mu \mathrm{g} / \mathrm{mL}$ ); [20] (3) $39 \mathrm{vs.} 18 \%$ (for cutoff $\geq 3.5 \mu \mathrm{g} / \mathrm{mL}$ ); [21] 4) 92 vs. $14 \%$ (for cutoff $>0.3 \mu \mathrm{g} / \mathrm{mL}$ ) [22]; and (5) $100 \mathrm{vs.}$ $80 \%$ (for cutoff $>5 \mu \mathrm{g} / \mathrm{mL}$ ) [22]. Moreover, there was a $66 \%$ lower likelihood to lose clinical response in case of 
drug concentrations above $3 \mu \mathrm{g} / \mathrm{mL}$ [23]. Clinical remission rates increased after dose escalation to reach target levels of $3-7 \mu \mathrm{g} / \mathrm{mL}$ (from 65 to $88 \%$ ) [24]. There was a longer duration of clinical response in patients with a threshold of $>12 \mu \mathrm{g} / \mathrm{mL}$ [25]. In addition, higher rates of endoscopic remission (47 vs. 19\%) were observed with detectable infliximab levels (vs. nondetectable) [19]. In UC, detectable infliximab levels were also associated with higher clinical (69 vs. 15\%) and endoscopic (76 vs. $28 \%$ ) response rates [26]. Patients in endoscopic remission had higher levels of infliximab (8.1 vs. 2.9) and an infliximab threshold level of $>6.6 \mu \mathrm{g} / \mathrm{mL}$ predicted endoscopic response with an OR of 18.1 [27]. In both UC and CD, loss of response to infliximab was attributed to low drug levels in $45 \%$ [28].

Fewer studies have been performed with adalimumab. In $\mathrm{CD}$, trough levels of $\geq 5 \mu \mathrm{g} / \mathrm{mL}$ have been identified as predictive for treatment continuity with an OR of 4.5 [29]. Higher trough levels were further observed with clinical remission and mucosal healing [30]. In UC, patients with histological and endoscopic inflammation had lower drug levels, while those in clinical remission and with mucosal healing showed higher serum concentrations of adalimumab [31]. A comprehensive analysis of 145 patients examined the impact of adalimumab and infliximab drug levels in both UC and CD [32]. The following rates of mucosal healing were found: (1) with infliximab $50 \%$ for $>4 \mu \mathrm{g} / \mathrm{mL}, 85 \%$ for $>6 \mu \mathrm{g} / \mathrm{mL}$, and $90 \%$ for $>8 \mu \mathrm{g} / \mathrm{mL}$ and (2) with adalimumab $50 \%$ for $>7.5 \mu \mathrm{g} / \mathrm{mL}$, $75 \%$ for $>8 \mu \mathrm{g} / \mathrm{mL}$, and $90 \%$ for $>12 \mu \mathrm{g} / \mathrm{mL}$ [32]. A plateau was reached with $>12 \mu \mathrm{g} / \mathrm{mL}$ (adalimumab) and $>8 \mu \mathrm{g} /$ $\mathrm{mL}$ (infliximab). For certolizumab, even fewer data are available: with higher drug levels $(\geq 23.30$ vs. $<8.98 \mu \mathrm{g} /$ $\mathrm{mL}$ ), more $\mathrm{CD}$ patients were found to be in clinical remission (93 vs. $50 \%$ ), endoscopic remission ( 75 vs. $30 \%$ ), and to show endoscopic response ( 87.5 vs. $20 \%$ ) [33].

Despite these positive data - however - in some trials, no association between drug levels and treatment outcome was seen: in the SONIC trial, no significant differences were observed in terms of remission rates at week 50 when patients with nondetectable infliximab levels $(0 \mu \mathrm{g} / \mathrm{mL})$ were compared with patients with higher drug levels $(>6 \mu \mathrm{g} / \mathrm{mL}, 67$ vs. $87 \%)[18,20]$. Similar findings were reported by Pariente et al. [34] In addition, optimal cutoff values remain unclear. This is mainly attributed to the fact that many different thresholds have been used in the so far conducted trials, ranging from $>1$ to $>12 \mu \mathrm{g} / \mathrm{mL}$ in case of infliximab. Different outcomes were used to define therapeutic response ranging from clinical response, remission to endoscopic response, and remission.
Since most data evolve from retrospective analyses of prospective studies, the evidence for TDM is low. The value of proactive drug level measurements and targeting infliximab treatment to a predefined serum concentration (target: $3-7 \mu \mathrm{g} / \mathrm{mL}$ ) were evaluated in the TAXIT trial: While indeed clinical remission rates increased with dose escalation in patients with subtherapeutic drug levels, this strategy was not superior to clinically based dosing [24]. Similarly, maintaining infliximab above $3 \mu \mathrm{g} / \mathrm{mL}$ did not result in higher rates of steroid-free clinical remission than adapting dose based only on symptoms (TAILORIX trial) [35]. Taken together, no clear recommendations for the use of TDM and for optimal thresholds in particular exist [7]. Suggested cutoffs vary from $>2$ to 5-10 $\mu \mathrm{g} / \mathrm{mL}$. Current recommendations regarding the use of TDM and adequate threshold levels in IBD patients are summarized in Table $1[9,10,36-40]$.

\section{Antidrug Antibodies}

Development of antidrug antibodies, a process called anti-TNF immunogenicity, may also affect the efficacy of anti-TNF treatment. Antidrug antibody formation has been observed with all anti-TNF agents used in IBD. Of note, episodic dosing resulted in higher antibody titers than did scheduled dosing [25, 41-45]. Antidrug antibodies have been linked to higher rates of loss of response and higher likelihood of transfusion reactions [25, 42, 43]. Antidrug antibody titers can be measured with commercially available tests, which are based on ELISA, RIA, or HMSA methods $[6,41,46]$. Data on the association between presence of antidrug antibodies and disease outcome are inconsistent [41]. In CD studies with episodic dosing of infliximab, higher antibody titers were linked to shorter duration of response and lower response rates, while no such association was seen with scheduled dosing except for the SONIC trial, where some improvement was observed with inconclusive antidrug antibody titers [19, $20,25,42-44]$. In UC, even higher response rates were seen with detectable antibodies, which were probably confounded by higher trough levels in these patients [47]. No such association was found in the study by Seow et al. [26]. For adalimumab and certolizumab, no associations between antidrug antibodies and disease outcome were seen $[14,48,49]$. Detailed descriptions of these trials can be found in the thorough reviews by Scott and Lichtenstein [41] and by Khanna et al. [6, 41]. No clear cutoffs for antidrug antibodies exist due to different measurement methods and the fact that antidrug antibodies may be only transient in a considerable proportion of patients. While some studies used absence vs. presence of antibod- 
Table 1. Current recommendations regarding drug levels and antidrug antibodies in IBD

\begin{tabular}{|c|c|c|c|c|c|}
\hline & $\mathrm{ECCO}$ & AGA & ACG & WGO & APAGE \\
\hline Use of TDM & $\begin{array}{l}\text { Could be used to } \\
\text { guide optimisation } \\
\text { strategy if available }\end{array}$ & $\begin{array}{l}\text { Reactive TDM } \\
\text { suggested to guide } \\
\text { treatment changes } \\
\text { if active anti-TNF } \\
\text { treated IBD }\end{array}$ & $\begin{array}{l}\text { Should be } \\
\text { considered in } \\
\text { active disease }\end{array}$ & $\begin{array}{l}\text { More widely available } \\
\text { for infliximab than } \\
\text { any other anti-TNF. } \\
\text { It can help determine } \\
\text { the cause of a secondary } \\
\text { loss of response and } \\
\text { may be adopted in dose } \\
\text { reduction strategies }\end{array}$ & No statement \\
\hline $\begin{array}{l}\text { Threshold for } \\
\text { adequate } \\
\text { drug levels }\end{array}$ & No statement & $\begin{array}{l}\text { Infliximab } \geq 5 \mu \mathrm{g} / \mathrm{mL} \\
\text { Adalimumab } \geq 7.5 \mu \mathrm{g} / \mathrm{mL} \\
\text { Certolizumab } \geq 20 \mu \mathrm{g} / \mathrm{mL} \\
\text { Golimumab unknown }\end{array}$ & $\begin{array}{l}\text { Infliximab }>7.5 \mu \mathrm{g} / \mathrm{mL} \text {, } \\
\text { adalimumab }>5 \mu \mathrm{g} / \mathrm{mL} \text {, } \\
\text { and certolizumab } \\
\text { pegol }>20 \mu \mathrm{g} / \mathrm{mL}\end{array}$ & No statement & No statement \\
\hline $\begin{array}{l}\text { Use of antidrug } \\
\text { antibodies }\end{array}$ & $\begin{array}{l}\text { Could be used to } \\
\text { guide optimization } \\
\text { strategy if available }\end{array}$ & No statement & $\begin{array}{l}\text { Should be considered } \\
\text { in active disease }\end{array}$ & $\begin{array}{l}\text { More widely available } \\
\text { for infliximab than } \\
\text { any other anti-TNF. } \\
\text { It can help determine } \\
\text { the cause of a secondary } \\
\text { loss of response and } \\
\text { may be adopted in dose } \\
\text { reduction strategies }\end{array}$ & No statement \\
\hline $\begin{array}{l}\text { Cut-off values for } \\
\text { antidrug antibodies }\end{array}$ & No statement & No statement & No statement & No statement & No statement \\
\hline
\end{tabular}

IBD, inflammatory bowel disease; ACG, American College of Gastroenterology; AGA, American Gastroenterology Association; APAGE, Asian Pacific Association of Gastroenterology; ECCO, European Crohn's and Colitis Organisation; WGO, World Gastroenterology Organisation.

ies, others used defined threshold values. There are no clear recommendations regarding the use of antidrug antibodies in IBD treatment. In addition, there is no consensus regarding adequate threshold values (Table 1). However, antidrug antibody titers may have their value in clinical practice. A study from the Mayo Clinic revealed higher response rates for switch of anti-TNF agent compared to dose intensification in case of presence of antidrug antibodies (92 vs. 17\%), while dose intensification was more effective if no antidrug antibodies were present ( 86 vs. $33 \%$ compared to switch of anti-TNF agent) [28]. Similarly, Roblin et al. [50] demonstrated high clinical response rates (67\%) with adalimumab dose optimization in case of low trough levels and nondetectable antidrug antibodies. In addition, combined interval shortening and dose intensification appears to be particularly effective for restoring therapeutic drug levels when antidrug antibodies titers are low [51]. Nonetheless, dose intensifications can still be effective even in case of high antidrug antibody titers (in 60\% compared to $74 \%$ efficacy in patients with nondetectable antidrug antibodies) [34].

\section{Methods}

\section{Delphi-Style Consensus}

To establish a consensus on the use of TDM in the context of loss of response to anti-TNF treatment, we performed a vote among IBD experts using a Delphi-style process [52]. First, we conducted a literature review using PubMed and Embase. The following key search items were used: loss of response, TDM, anti$T N F$, antidrug antibodies, and IBD. In addition, guidelines from 5 gastroenterology societies were consulted: American Gastroenterology Association, American College of Gastroenterology, ECCO, Asian Pacific Association of Gastroenterology and World Gastroenterology Organisation. In a second step, 8 IBD specialists participated in a 3-h meeting and rated different statements on an even Likert-scale ranging from 1 to 4 , based on their expert opinion and the available literature: 1 indicated strong disagreement with a specific statement, 2 disagreement, 3 agreement, and 4 indicated strong agreement. The statements included (i) reason for and optimal time-point of TDM; (ii) use of antidrug antibodies; (iii) definition of loss of response; and (iv) most adequate treatment strategies in case of loss of response to anti-TNF. A list of the statements used for the first round of voting can be found in online Supplementary Table 1 (for all online suppl. material, see www. karger.com/doi/10.1159/000501930). Participants were blinded to the votes of the other IBD experts. The voting process was followed by a panel discussion to refine the statements. A statement was
Greuter et al. 


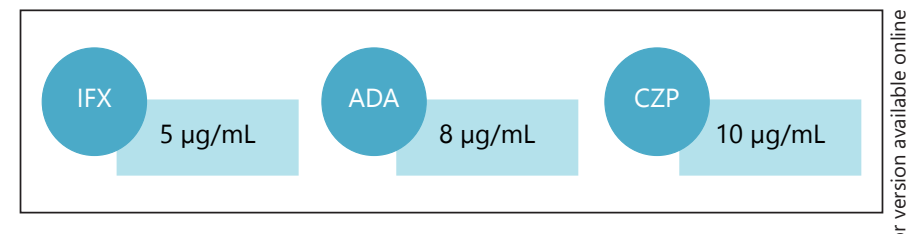

Fig. 1. Thresholds for adequate drug levels according to anti-TNF agent. ADA, adalimumab; CZP, certolizumab pegol; IFX, infliximab.

considered accepted if the mean rating value was 3 or more. As data are limited for biologics beyond the anti-TNF mode of action, statements were restricted to anti-TNF treatment. The 8 IBD experts were as follows: 5 experts practice in and/or are affiliated with an academic institution (university hospital level), 2 experts practice in private practice, and 1 expert practices at a large community hospital (all in Switzerland, Europe).

\section{Ethical Statement}

This study did not include patient subjects. Therefore, as for other Delphi-technique based consensus paper, ethical approval was not required [53].

\section{Results}

\section{TDM for Anti-TNF}

After the specialist panel opinion, the following consensus on therapeutic drug levels was achieved: (1) loss of response is associated with low or undetectable serum drug concentration in $50-70 \%$ of cases (mean value 3.4 , online Suppl. Fig. 1) and (2) both in CD and UC, loss of response is associated with low or undetectable serum drug levels (mean value 3.6, online Suppl. Fig. 1). There was a consensus on how anti-TNF clearance occurs: through immune-mediated reactions (with formation of antidrug antibodies, mean value 3.6) and nonimmune reactions (mean value 3.6, online Suppl. Fig. 1). There was strong agreement that nonimmune-mediated drug clearance is affected by severity and extent of IBD (mean value 3.9), male sex (mean value 3.3), BMI (mean value 3.5), and concomitant use of immunomodulators (mean value 3.8, online Suppl. Fig. 2). There was also strong consensus on when to measure drug concentrations in terms of infliximab (trough levels immediately before the administration of the next dose, mean value 4). However, there was no consensus regarding when to measure drug concentrations of subcutaneously administered anti-TNF. In terms of adequate anti-TNF levels, there was strong agreement that mucosal healing should be the target to treat. Optimal cutoff values to achieve this goal were controversially discussed (online Suppl. Fig. 3). However, there was a final agreement for infliximab $(5 \mu \mathrm{g} / \mathrm{mL})$, adalimumab $(8 \mu \mathrm{g} / \mathrm{mL})$, and certolizumab pegol $(10 \mu \mathrm{g} /$ $\mathrm{mL}$, Fig. 1). There was no agreement regarding an optimal threshold for golimumab.

\section{Antidrug Antibodies}

In a next step, use of and cutoff values for antidrug antibodies were rated and discussed. There was overall agreement that high antidrug antibody titers are predictive for adverse events and loss of response, but that they do not predict mucosal healing, CRP levels, or calprotectin levels (online Suppl. Fig. 4). There was consensus to use manufacturer's cutoff values for anti-infliximab and adalimumab antibody titers. The test provider usually indicates if levels are considered positive or negative. All positive levels are meaningful. In addition, there was an overall agreement that antidrug antibodies should be measured when drug levels are lowest to avoid the risk of complex formation. There was no consensus on specific cutoff values for certolizumab pegol and golimumab. The value of anti-vedolizumab antibodies remains unclear and was not within the scope of the current consensus.

\section{Loss of Response to Anti-TNF}

There was overall agreement on how to define loss of response. The following parameters should be considered: symptoms (mean value 3.4), drug levels (mean value 3.1), antidrug antibodies (mean value 3.1), and imaging such as sonography (mean value 3.1 ), endoscopy (mean value of 3.5), and MRI (in case of Crohn's disease, mean value 3.1, online Suppl. Fig. 5). A calprotectin level of $>50$ $\mu \mathrm{g} / \mathrm{g}$ was not considered to affect clinical decision making (mean value 2.6). However, after discussing optimal cutoff levels, there was a strong agreement that calprotectin levels of $>200 \mu \mathrm{g} / \mathrm{g}$ should be taken into account, when defining loss of response.

\section{Therapeutic Algorithm for Patients with Loss of \\ Response to Anti-TNF}

The following interventions were deemed appropriate in the context of loss of response: (1) shortening of dose interval or dose intensification in case of subtherapeutic drug levels, and absent or low antidrug antibody titers; (2) switch to another anti-TNF (= switch in class) in case of subtherapeutic drug levels, but presence of antidrug antibodies; and (3) switch to a non-anti-TNF biologic (= switch out of class) in case of therapeutic drug levels regardless of presence or absence of antidrug antibodies. In case of subtherapeutic drug levels, but absent or low antidrug antibody titers, 2 options were deemed appropriate: (1) increasing the dose ("dose intensification") or (2) shortening the interval. The 
Fig. 2. Treatment algorithm in case of loss of response to anti-TNF. ADA, antidrug antibody; CS, corticosteroids; IBD, inflammatory bowel disease; IS, immunosuppressive drugs.

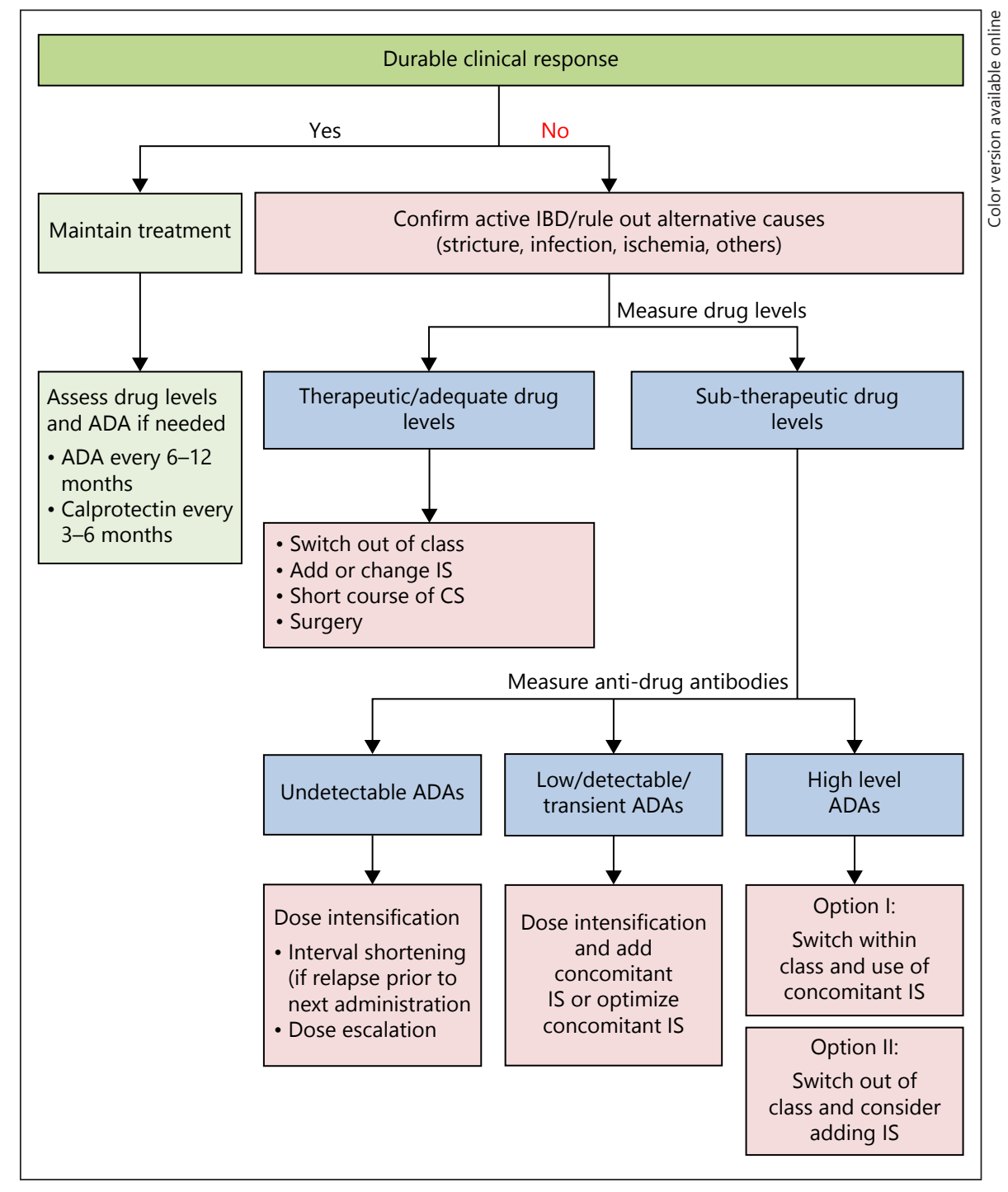

experts agreed on the following: (1) dose intensification should be strived for if the clinical effect after drug administration is slow and (2) shortening the interval should be favored if a patient still responds to a maintenance dose, but experiences deterioration of IBD symptoms prior to the next drug administration. Figure 2 shows a treatment algorithm in case of loss of response to anti-TNF, which was elaborated during this expert panel discussion.

\section{Discussion}

TDM and measurement of antidrug antibodies are increasingly used in the context of loss of response to antiTNF. As of yet, ECCO guidelines mention these novel tools but without clear recommendations about their use
$[9,10]$. We herein report on the results from a Delphibased consensus meeting among 8 IBD specialists. The final statements are summarized in Table 2.

Our expert panel reached consensus that loss of response to anti-TNF is associated with inadequate antiTNF drug levels in both CD and UC. Indeed, despite some negative data from the SONIC trial, most published analyses showed that higher trough levels lead to better clinical and endoscopic outcomes $[18,20]$. Most data are available for infliximab, but similar results have been reported for other anti-TNF agents. There was consensus that drug levels should be measured, when concentration is lowest (= trough levels). However, optimal cutoff values were discussed controversially among the panel experts. Current data are limited by the fact that studies used many different thresholds to define adequate and nonadequate drug con- 
Table 2. Overview of the final statements made during the expert panel discussion

Final statements

Loss of response is associated with inadequate drug levels in both CD and UC

Best time-point for measuring drug levels is prior to the next application (trough levels)

Thresholds for adequate drug levels depend on the anti-TNF agent

Antidrug antibodies are predictive for loss of response and adverse events

Manufacturer's cutoff values for antidrug antibodies should be used and all positive levels should be considered meaningful

Antidrug antibody titers and drug trough levels are key determinants in the treatment algorithm

centrations. Nonetheless, a second voting round resulted in a consensus for infliximab $(5 \mu \mathrm{g} / \mathrm{mL})$, adalimumab $(8 \mu \mathrm{g} / \mathrm{mL})$, and certolizumab pegol $(10 \mu \mathrm{g} / \mathrm{mL})$. These cutoffs should be seen as guiding values. Such guidance may help clinicians to decide whether or not a current anti-TNF therapy is underdosed. A limiting factor of the current recommendation is that it may take up to 2 weeks until antiTNF drug levels are available. Thus, an intervention is often needed and performed before the results are known. Point-of-care measures of anti-TNF may allow clinicians to take more advantage of TDM in the future.

Available data for antidrug antibodies are less consistent than they are for drug concentrations [41]. However, our expert panel reached consensus that antidrug antibody titers are useful and high titers are associated with loss of response to anti-TNF. This agreement was achieved based on (1) data from the SONIC trial [20], (2) a recent meta-analysis showing worse outcome with antidrug antibodies at least in CD [54], (3) and the fact that - if antidrug antibodies are present - switch to another anti-TNF results in better clinical response than dose intensification [28]. Thus, antidrug antibodies should be taken into consideration when it comes to define loss of response to anti-TNF. However, threshold values remain unknown. As of today, any positive result evolving from antibody testing (based on the manufacturer's protocol) should be considered clinically meaningful.

Based on these data and agreements, both trough levels and antidrug antibody titers should be seen as key determinants in the treatment algorithm. After loss of response is confirmed, drug monitoring is recommended. If thera- peutic drug levels are detected, anti-TNF dose intensification has no benefit. Treatment should be switched out of class, high dose steroids might be started, or even surgery might be considered. In case of inadequate drug levels, antidrug antibody titers may help in clinical decision making: (1) undetectable antibody or low antibody titers justify dose intensification, while (2) high antidrug antibody titers should lead to a therapeutic switch out of class or maybe within class, but with optimization of concomitant immunomodulation. Some anti-TNF has lower immunogenic potential than others (e.g., adalimumab) [55]. This strategy is mainly based on the retrospective analysis from Mayo Clinic, where in patients with low drug levels dose intensification was superior to anti-TNF switching, but in patients with antidrug antibodies, switching to other agents was superior to dose escalation [28]. In another study - however - dose intensification was effective even in patients with high antidrug antibody titers [34].

Our consensus recommendations have several limitations. They only discuss anti-TNF treatment, since conclusive data are still missing for the newer non-anti-TNF biologics. Measuring vedolizumab levels is complicated because of saturation of the target receptor. In addition, patients may be in clinical remission despite undetectable or very low vedolizumab levels. Ustekinumab trough levels can now be measured. However, data supporting their use in clinical practice are too sparse [7]. The literature review was not conducted in the sense of a systematic review, but rather based on recent meta-analyses, reviews, guidelines, and studies in high impact journals. A further limitation of our consensus is that there is still no generally accepted definition for loss of response to anti-TNF. Therefore, the therapeutic algorithm provided in Figure 2 should be seen as guidance rather than a rule for every patient. Clinical decision making should be discussed on individual basis.

In conclusion, a Delphi-style consensus among 8 IBD experts shows that TDM and measurement of antidrug antibody titers are useful in the context of loss of response to anti-TNF. Optimal cutoff levels depend on the type of anti-TNF. These values are critical in the decision-making process. More studies are needed to address the value of such measurements for non-anti-TNF biologics.

\section{Disclosure Statement}

T.G. is a consultant for Sanofi Aventis, received a travel grant from Falk Pharma GmbH and Vifor, and an unrestricted research grant from Novartis. S.R.V. received consultant fees and unrestricted research grants from Vifor, Sanofi Aventis and Falk Pharma $\mathrm{GmbH}$. P.M. received consulting fees from AbbVie, Calypso, Ferring 
Pharmaceuticals, Merck Serono, MSD, Nestlé Health Sciences, Pfizer, Takeda, UCB Pharma, and Vifor Pharma, lecture fees from AbbVie, Ferring Pharmaceuticals, Hospira, MSD, Takeda, UCB Pharma, and Vifor Pharma and research grants from MSD, Takeda, and UCB Pharma. G.R. has consulted to Abbvie, Augurix, BMS, Boehringer, Calypso, Celgene, FALK, Ferring, Fisher, Genentech, Gilead, Janssen, MSD, Novartis, Pfizer, Phadia, Roche, UCB, Takeda, Tillots, Vifor, Vital Solutions, and Zeller; has received speaker's honoraria from Astra Zeneca, Abbvie, FALK, Janssen, MSD, Pfizer, Phadia, Takeda, Tillots, UCB, Vifor, and Zeller; and has received educational grants and research grants from Abbvie, Ardeypharm, Augurix, Calypso, FALK, Flamentera, MSD, Novartis, Pfizer, Roche, Takeda, Tillots, UCB, and Zeller. M.H.M. received consultant fees from Abbvie, Calypso, Ferring, MSD, Pfizer, Takeda and Vifor as well as unrestricted grants from Vifor, UCB, and Takeda. The other authors report no conflict of interest. No company representative was involved in conception, writing, or financing of this study.

\section{Author contributions}

G.R., N.Z., and S.R.V.: study design; TG, A.M.S., and S.R.V.: literature research; T.G., P.J., P.M., F.S., C.M., B.S., M.M., G.R., and S.R.V.: acquisition and interpretation of data; T.G., M.M., and S.R.V.: drafting of manuscript; P.J., P.M., F.S., C.M., B.S., M.M., G.R., and S.R.V.: expert panel discussion for the Delphi-like process. P.J., P.M., F.S., C.M., N.Z., B.S., M.M., A.M.S., and G.R.: critical review of the manuscript. T.G., M.M., G.R., and S.R.V.: supervision. All authors contributed to the critical revision and approved the final version of manuscript.

\section{Guarantors of the Article}

Thomas Greuter, MD and Stephan R. Vavricka, MD.

\section{References}

1 Vavricka SR, Gubler M, Gantenbein C, Spoerri M, Froehlich F, Seibold F, et al.; Swiss IBD Cohort Study Group. Anti-TNF Treatment for Extraintestinal Manifestations of Inflammatory Bowel Disease in the Swiss IBD Cohort Study. Inflamm Bowel Dis. 2017 Jul; 23(7):1174-81.

2 Kaser A, Zeissig S, Blumberg RS. Inflammatory bowel disease. Annu Rev Immunol. 2010; 28(1):573-621.

3 Vavricka SR, Schoepfer A, Scharl M, Lakatos PL, Navarini A, Rogler G. Extraintestinal Manifestations of Inflammatory Bowel Disease. Inflamm Bowel Dis. 2015 Aug;21(8): 1982-92.

4 Ben-Horin S, Chowers Y. Review article: loss of response to anti-TNF treatments in Crohn's disease. Aliment Pharmacol Ther. 2011 May;33(9):987-95.

5 Gisbert JP, Panés J. Loss of response and requirement of infliximab dose intensification in Crohn's disease: a review. Am J Gastroenterol. 2009 Mar;104(3):760-7.

6 Khanna R, Sattin BD, Afif W, Benchimol EI, Bernard EJ, Bitton A, et al. Review article: a clinician's guide for therapeutic drug monitoring of infliximab in inflammatory bowel disease. Aliment Pharmacol Ther. 2013 Sep; 38(5):447-59.

7 Heron V, Afif W. Update on Therapeutic Drug Monitoring in Crohn's Disease. Gastroenterol Clin North Am. 2017 Sep;46(3):64559.

8 Kopylov U, Seidman E. Predicting durable response or resistance to antitumor necrosis factor therapy in inflammatory bowel disease. Therap Adv Gastroenterol. 2016 Jul;9(4): 513-26.

9 Gomollón F, Dignass A, Annese V, Tilg H, Van Assche G, Lindsay JO, et al.; ECCO. 3rd European Evidence-based Consensus on the Diagnosis and Management of Crohn's Disease 2016: Part 1: Diagnosis and Medical
Management. J Crohn's Colitis. 2017 Jan; 11(1):3-25.

10 Harbord M, Eliakim R, Bettenworth D, Karmiris K, Katsanos K, Kopylov U, et al.; European Crohn's and Colitis Organisation [ECCO]. Third European Evidence-based Consensus on Diagnosis and Management of Ulcerative Colitis. Part 2: current Management. J Crohn's Colitis. 2017 Jul;11(7):769-84.

11 Hyams J, Crandall W, Kugathasan S, Griffiths A, Olson A, Johanns J, et al.; REACH Study Group. Induction and maintenance infliximab therapy for the treatment of moderateto-severe Crohn's disease in children. Gastroenterology. 2007 Mar;132(3):863-73.

12 Allez M, Karmiris K, Louis E, Van Assche G, Ben-Horin S, Klein A, et al. Report of the ECCO pathogenesis workshop on anti-TNF therapy failures in inflammatory bowel diseases: definitions, frequency and pharmacological aspects. J Crohn's Colitis. 2010 Oct; 4(4):355-66.

13 Regueiro M, Siemanowski B, Kip KE, Plevy S. Infliximab dose intensification in Crohn's disease. Inflamm Bowel Dis. 2007 Sep;13(9): 1093-9.

14 Karmiris K, Paintaud G, Noman M, Magdelaine-Beuzelin C, Ferrante M, Degenne D, et al. Influence of trough serum levels and immunogenicity on long-term outcome of adalimumab therapy in Crohn's disease. Gastroenterology. 2009 Nov;137(5):1628-40.

15 de Ridder L, Rings EH, Damen GM, Kneepkens CM, Schweizer JJ, Kokke FT, et al. Infliximab dependency in pediatric Crohn's disease: long-term follow-up of an unselected cohort. Inflamm Bowel Dis. 2008 Mar;14(3): 353-8.

16 Higgins PD, Schwartz M, Mapili J, Krokos I, Leung J, Zimmermann EM. Patient defined dichotomous end points for remission and clinical improvement in ulcerative colitis. Gut. 2005 Jun;54(6):782-8.
17 Sandborn WJ, van Assche G, Reinisch W, Colombel JF, D'Haens G, Wolf DC, et al. Adalimumab induces and maintains clinical remission in patients with moderate-to-severe ulcerative colitis. Gastroenterology. 2012 Feb; 142(2):257-65.e1-3.

18 Sorrentino D, Nguyen V, Henderson C, Bankole A. Therapeutic Drug Monitoring and Clinical Outcomes in Immune Mediated Diseases: The Missing Link. Inflamm Bowel Dis. 2016 Oct;22(10):2527-37.

19 Maser EA, Villela R, Silverberg MS, Greenberg GR. Association of trough serum infliximab to clinical outcome after scheduled maintenance treatment for Crohn's disease. Clin Gastroenterol Hepatol. 2006 Oct;4(10): 1248-54.

20 Colombel JF, Sandborn WJ, Reinisch W, Mantzaris GJ, Kornbluth A, Rachmilewitz D, et al.; SONIC Study Group. Infliximab, azathioprine, or combination therapy for Crohn's disease. N Engl J Med. 2010 Apr; 362(15):1383-95.

21 Cornillie F, Hanauer SB, Diamond RH, Wang J, Tang KL, Xu Z, et al. Postinduction serum infliximab trough level and decrease of C-reactive protein level are associated with durable sustained response to infliximab: a retrospective analysis of the ACCENT I trial. Gut. 2014 Nov;63(11):1721-7.

22 Drobne D, Bossuyt P, Breynaert C, Cattaert T, Vande Casteele N, Compernolle G, et al. Withdrawal of immunomodulators after cotreatment does not reduce trough level of infliximab in patients with Crohn's disease. Clin Gastroenterol Hepatol. 2015 Mar;13(3):514521.e4.

23 Bortlik M, Duricova D, Malickova K, Machkova N, Bouzkova E, Hrdlicka L, et al. Infliximab trough levels may predict sustained response to infliximab in patients with Crohn's disease. J Crohn's Colitis. 2013 Oct;7(9):73643. 
24 Vande Casteele N, Ferrante M, Van Assche G, Ballet V, Compernolle G, Van Steen K, et al. Trough concentrations of infliximab guide dosing for patients with inflammatory bowel disease. Gastroenterology. 2015 Jun;148(7): 1320-9.e3.

25 Baert F, Noman M, Vermeire S, Van Assche G, D’ Haens G, Carbonez A, et al. Influence of immunogenicity on the long-term efficacy of infliximab in Crohn's disease. N Engl J Med. $2003 \mathrm{Feb} ; 348(7): 601-8$.

26 Seow $\mathrm{CH}$, Newman A, Irwin SP, Steinhart AH, Silverberg MS, Greenberg GR. Trough serum infliximab: a predictive factor of clinical outcome for infliximab treatment in acute ulcerative colitis. Gut. 2010 Jan;59(1):49-54.

27 Brandse JF, Mathôt RA, van der Kleij D, Rispens T, Ashruf Y, Jansen JM, et al. Pharmacokinetic Features and Presence of Antidrug Antibodies Associate With Response to Infliximab Induction Therapy in Patients With Moderate to Severe Ulcerative Colitis. Clin Gastroenterol Hepatol. 2016 Feb;14(2):2518.e1-2.

28 Afif W, Loftus EV Jr, Faubion WA, Kane SV, Bruining DH, Hanson KA, et al. Clinical utility of measuring infliximab and human antichimeric antibody concentrations in patients with inflammatory bowel disease. Am J Gastroenterol. 2010 May;105(5):1133-9.

29 Baert F, Kondragunta V, Lockton S, Vande Casteele N, Hauenstein S, Singh S, et al. Antibodies to adalimumab are associated with $\mathrm{fu}$ ture inflammation in Crohn's patients receiving maintenance adalimumab therapy: a post hoc analysis of the Karmiris trial. Gut. 2016 Jul;65(7):1126-31.

30 Roblin X, Marotte H, Rinaudo M, Del Tedesco E, Moreau A, Phelip JM, et al. Association between pharmacokinetics of adalimumab and mucosal healing in patients with inflammatory bowel diseases. Clin Gastroenterol Hepatol. 2014 Jan;12(1):80-84.e2.

31 Yarur AJ, Jain A, Hauenstein SI, Quintero MA, Barkin JS, Deshpande AR, et al. Higher Adalimumab Levels Are Associated with Histologic and Endoscopic Remission in Patients with Crohn's Disease and Ulcerative Colitis. Inflamm Bowel Dis. 2016 Feb;22(2):409-15.

32 Ungar B, Levy I, Yavne Y, Yavzori M, Picard O, Fudim E, et al. Optimizing Anti-TNF-a Therapy: Serum Levels of Infliximab and Adalimumab Are Associated With $\mathrm{Mu}$ cosal Healing in Patients With Inflammatory Bowel Diseases. Clin Gastroenterol Hepatol. 2016 Apr;14(4):550-557.e2.

33 Colombel JF, Sandborn WJ, Allez M, Dupas JL, Dewit O, D'Haens G, et al. Association between plasma concentrations of certolizumab pegol and endoscopic outcomes of patients with Crohn's disease. Clin Gastroenterol Hepatol. 2014 Mar;12(3):423-31.e1.

34 Pariente B, Pineton de Chambrun G, Krzysiek R, Desroches M, Louis G, De Cassan C, et al. Trough levels and antibodies to infliximab may not predict response to intensification of infliximab therapy in patients with inflamma- tory bowel disease. Inflamm Bowel Dis. 2012 Jul;18(7):1199-206.

35 D'Haens G, Vermeire S, Lambrecht G, Baert F, Bossuyt P, Pariente B, et al.; GETAID. Increasing Infliximab Dose Based on Symptoms, Biomarkers, and Serum Drug Concentrations Does Not Increase Clinical, Endoscopic, and Corticosteroid-Free Remission in Patients With Active Luminal Crohn's Disease. Gastroenterology. 2018 Apr; 154(5): 1343-1351.e1.

36 Feuerstein JD, Nguyen GC, Kupfer SS, FalckYtter Y, Singh S; American Gastroenterological Association Institute Clinical Guidelines Committee. American Gastroenterological Association Institute Guideline on Therapeutic Drug Monitoring in Inflammatory Bowel Disease. Gastroenterology. 2017 Sep;153(3): 827-34.

37 Lichtenstein GR, Loftus EV, Isaacs KL, Regueiro MD, Gerson LB, Sands BE. ACG Clinical Guideline: Management of Crohn's Disease in Adults. Am J Gastroenterol. 2018 Apr; 113(4):481-517.

38 Bernstein CN, Eliakim A, Fedail S, Fried M, Gearry R, Goh KL, et al.; Review Team. World Gastroenterology Organisation Global Guidelines Inflammatory Bowel Disease: update August 2015. J Clin Gastroenterol. 2016 Nov/Dec;50(10):803-18.

39 Ooi CJ, Fock KM, Makharia GK, Goh KL, Ling KL, Hilmi I, et al.; Asia Pacific Association of Gastroenterology Working Group on Inflammatory Bowel Disease. The Asia-Pacific consensus on ulcerative colitis. J Gastroenterol Hepatol. 2010 Mar;25(3):453-68.

40 Ooi CJ, Makharia GK, Hilmi I, Gibson PR, Fock KM, Ahuja V, et al.; Asia Pacific Association of Gastroenterology (APAGE) Working Group on Inflammatory Bowel Disease. Asia-Pacific consensus statements on Crohn's disease. Part 2: management. J Gastroenterol Hepatol. 2016 Jan;31(1):56-68.

41 Scott FI, Lichtenstein GR. Therapeutic Drug Monitoring of Anti-TNF Therapy in Inflammatory Bowel Disease. Curr Treat Options Gastroenterol. 2014 Mar;12(1):59-75.

42 Farrell RJ, Alsahli M, Jeen YT, Falchuk KR, Peppercorn MA, Michetti P. Intravenous hydrocortisone premedication reduces antibodies to infliximab in Crohn's disease: a randomized controlled trial. Gastroenterology. 2003 Apr;124(4):917-24.

43 Vermeire S, Noman M, Van Assche G, Baert F, D'Haens G, Rutgeerts P. Effectiveness of concomitant immunosuppressive therapy in suppressing the formation of antibodies to infliximab in Crohn's disease. Gut. 2007 Sep; 56(9):1226-31.

44 Hanauer SB, Wagner CL, Bala M, Mayer L, Travers S, Diamond RH, et al. Incidence and importance of antibody responses to infliximab after maintenance or episodic treatment in Crohn's disease. Clin Gastroenterol Hepatol. 2004 Jul;2(7):542-53.

45 Hanauer SB, Feagan BG, Lichtenstein GR, Mayer LF, Schreiber S, Colombel JF, et al.;
ACCENT I Study Group. Maintenance infliximab for Crohn's disease: the ACCENT I randomised trial. Lancet. 2002 May;359(9317): 1541-9.

46 Wang SL, Ohrmund L, Hauenstein S, Salbato J, Reddy R, Monk P, et al. Development and validation of a homogeneous mobility shift assay for the measurement of infliximab and antibodies-to-infliximab levels in patient serum. J Immunol Methods. 2012 Aug;382(12):177-88.

47 Rutgeerts P, Sandborn WJ, Feagan BG, Reinisch W, Olson A, Johanns J, et al. Infliximab for induction and maintenance therapy for ulcerative colitis. N Engl J Med. 2005 Dec; 353(23):2462-76

48 Schreiber S, Khaliq-Kareemi M, Lawrance IC, Thomsen OØ, Hanauer SB, McColm J, et al.; PRECISE 2 Study Investigators. Maintenance therapy with certolizumab pegol for Crohn's disease. N Engl J Med. 2007 Jul;357(3):23950.

49 Sandborn WJ, Abreu MT, D’Haens G, Colombel JF, Vermeire S, Mitchev K, et al. Certolizumab pegol in patients with moderate to severe Crohn's disease and secondary failure to infliximab. Clin Gastroenterol Hepatol. 2010 Aug;8(8):688-695.e2.

50 Roblin X, Rinaudo M, Del Tedesco E, Phelip JM, Genin C, Peyrin-Biroulet L, et al. Development of an algorithm incorporating pharmacokinetics of adalimumab in inflammatory bowel diseases. Am J Gastroenterol. 2014 Aug;109(8):1250-6.

51 Dreesen E, Van Stappen T, Ballet V, Peeters M, Compernolle G, Tops S, et al. Anti-infliximab antibody concentrations can guide treatment intensification in patients with Crohn's disease who lose clinical response. Aliment Pharmacol Ther. 2018 Feb;47(3): 346-55.

52 Prinsen CA, Vohra S, Rose MR, King-Jones S, Ishaque $\mathrm{S}$, Bhaloo $\mathrm{Z}$, et al. Core Outcome Measures in Effectiveness Trials (COMET) initiative: protocol for an international Delphi study to achieve consensus on how to select outcome measurement instruments for outcomes included in a 'core outcome set'. Trials. 2014 Jun;15(1):247.

53 Vuitton L, Peyrin-Biroulet L, Colombel JF, Pariente B, Pineton de Chambrun G, Walsh AJ, et al. Defining endoscopic response and remission in ulcerative colitis clinical trials: an international consensus. Aliment Pharmacol Ther. 2017 Mar;45(6): 801-13.

54 Nanda KS, Cheifetz AS, Moss AC. Impact of antibodies to infliximab on clinical outcomes and serum infliximab levels in patients with inflammatory bowel disease (IBD): a metaanalysis. Am J Gastroenterol. 2013 Jan;108(1): 40-7.

55 Chaparro M, Guerra I, Muñoz-Linares P, Gisbert JP. Systematic review: antibodies and anti-TNF- $\alpha$ levels in inflammatory bowel disease. Aliment Pharmacol Ther. 2012 May; 35(9):971-86. 